\title{
Development of Interior Finishing Unit Assembly System with Robot -WASCORIV Research Project Report (Part III)
}

Masatoshi Handa ${ }^{1}$, Yukio Hasegawa ${ }^{2}$, Hisashi Matsuda ${ }^{3}$, Kinya Tamaki ${ }^{4}$,

Sigeyuki Kojima ${ }^{5}$, Kohtarou Matsueda ${ }^{6}$, Tomoyuki Takakuwa ${ }^{7}$, and Takumi Onoda ${ }^{8}$

${ }^{1}$ Toda Corporation,

2 ,3System Sience Instytute, Waseda University,

${ }^{4}$ Aoyama Gakuin University,

${ }^{5}$ Tokyu Corporation,

${ }^{6}$ Kumagai Gumi Corporation,

${ }^{7}$ Sato Kogyo Corporation,

${ }^{8}$ Komatu Ltd, JAPAN

\section{Abstract}

The WASCOR (WASeda Construction Robot) research project was organized in 1982 by the System Science Institute, Waseda University, Tokyo, Japan, aiming at automatizing building constructions by robotics. This project is collaborated by nine general contractors and a construction machinery manufacturer.

WASCOR IV has been working on the Automatized Building Interior Finishing System. In the symposium last year, WASCOR IVreported a summary of the first year's outcome in the report:Part I, which includes the outline of this three-year-project aswell as the concept of Point Of Production System (POP System). In this symposium, Part II: Building System Design for Development of Automatized Interior Finishing System and Part III: Development of Interior Finishing unit Assembly System with Robot are presented. This paper, which covers the Part III, is composed of the following two sections: 1) the details of finishing units and building methods, and 2) the schematic design of construction robots.

\section{INTRODUCTION}

As reported in the Part II, the automation has been put into practical use for skeleton work, whereas neither mechanization nor automation in interior finishing work as a total system are enthusiastically studied. Some kinds of construction robots for interior work which are considered repetitive and monotonous work, such as setting board on frame, has been developed. However, the research of automation in terms of the whole process of finishing work is hardly seen.

Interior finishing work consists of many phases of works requiring different skill, which makes the process of the work intricate. The project has been trying to develop the building system whitch can easily been fabricated with robot and propose the schematic drawings of the robots to be used. 


\section{THE OUTLINE OF THE BUILDING SYSTEM}

After finishing skeleton construction work, usually finishing work is completed by the follwing sequence: furring strips, frames for openings, pipngs, dry-walls, wallpapering and fitting of fixtures etc., as well as setting scaffordings to some of the works. The conventional method of finishing work has many problems to be improved because of the cmplicated work process mentiond above.

The project proposes a building method which is carried out by assembling factory-made interior units installed with frames, boads, papers, and fixtures, using construction robots.

Considering the dimentional variety of skeleton and interior units, as well as setting variety, adjustable quick acting joint which has the tolerance $(7 \mathrm{~mm})$ is designed to make the interior finishing work more easily to be with robots. The prototipical building is designed based on a specific module and standardized members so that the numbers of dimentional types of the units are decreased by $25 \%$ comparing with conventional building design .

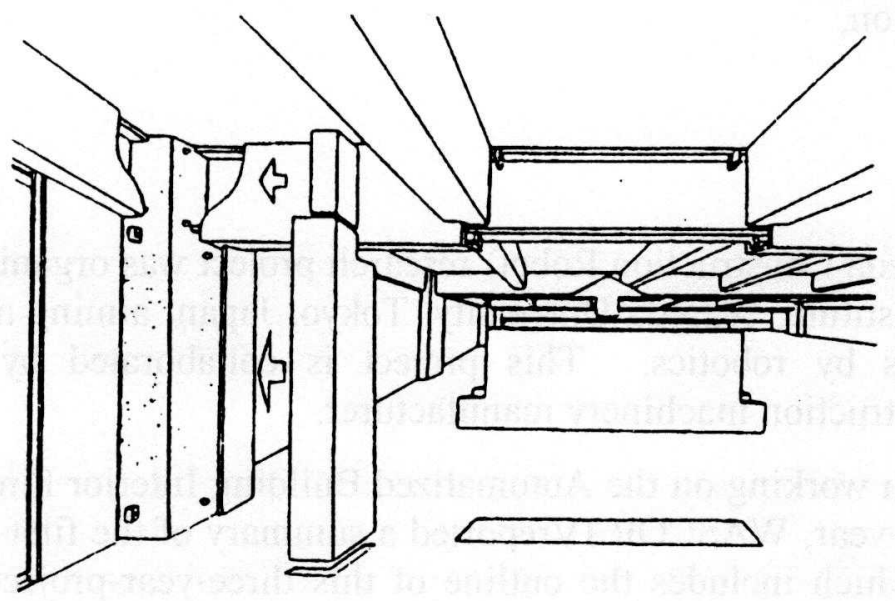

Figure 1. An image which wall, beam and column units are fabricated

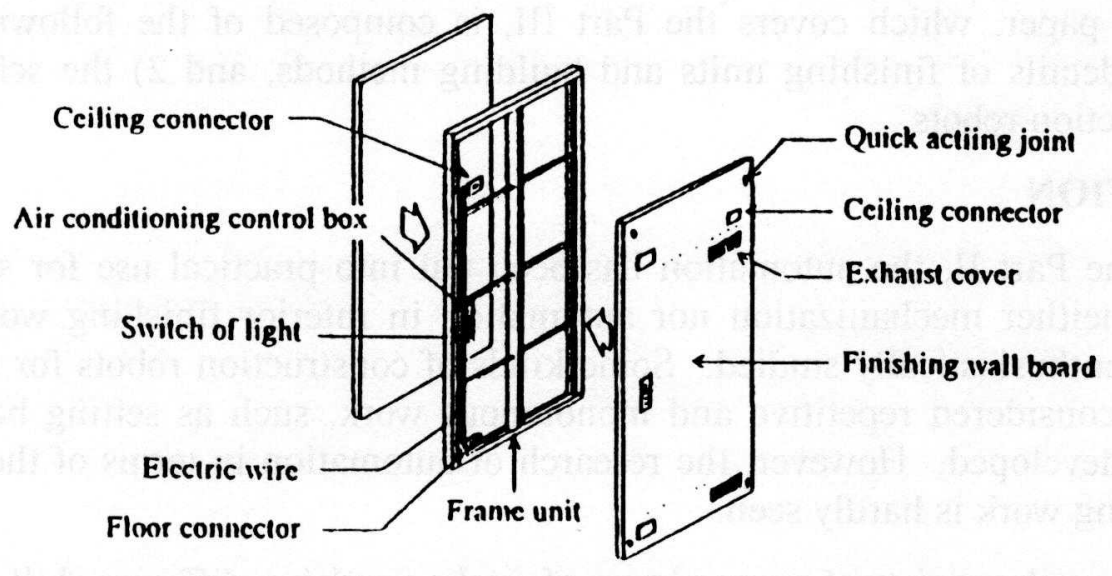

Figure 2. Detail of wall unit 


\subsection{Wall Unit, Beam Unit, and Column Unit}

Such as fig. 3 shown,fandamentally, the height of the wall unit is up to the bottom of the upper slab, while the constraint of handling makes the maximum width of the unit $1 \mathrm{~m}$.

The frame of wall unit consists of normal light gauge steel at the core, and channel steel are used for the upper and bottom edge, at where the quick acting joints are fitted. Each party wall has the quick acting joint on the wall face where the ceiling unit is fixed.

The project selected calcium-silicate-board finished by fabric wall covering instead of other alternatives, such as gypsum boad and wall paper, steel boad and painting, etc. The fire proof walls and the main partitioning walls are finished on the both sides, but the back face of an peripherial wall is not finished. Some walls are installed with outlets, switch of electorical fixtures, ventirators, etc.

Column units and beam units covering the skeleton are made of fire proof calciumsilicate-board and fabric wall covering, but they don't need frame because these unit are used only to cover the column and the beam. Structural beams concealed by the ceiling units are covered only by calcium silicate board if it is required. The height of the column units are the distance between the top of the floor and the bottom of the upper slab, and the length of the beam units is distance approx. $3 \mathrm{~m}$.

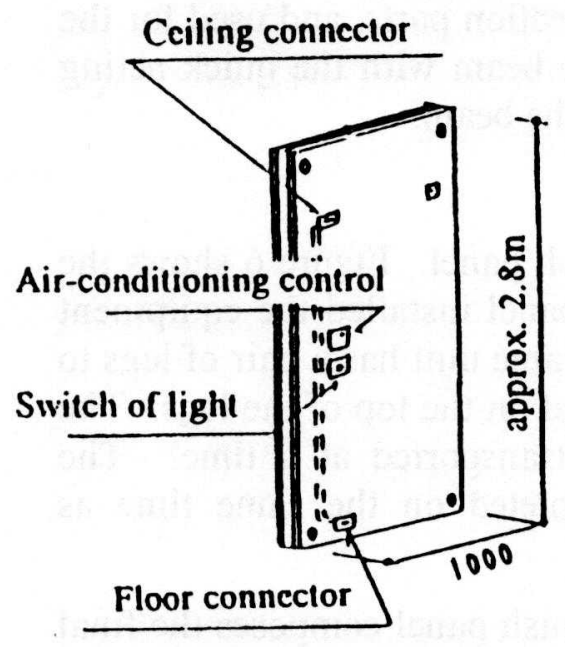

Wall basic unit

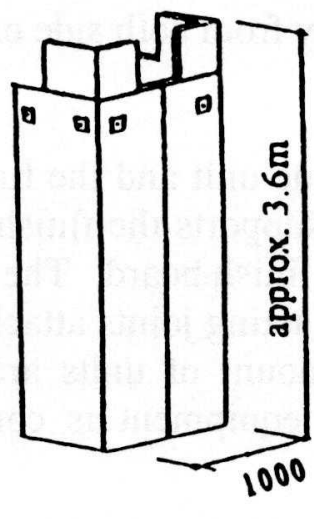

Column basic unit

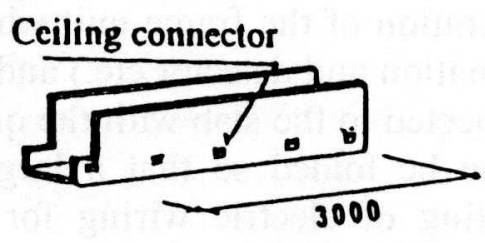

Beam basic unit

Figure 3, Wall Unit, Column Unit, and Beam unit 


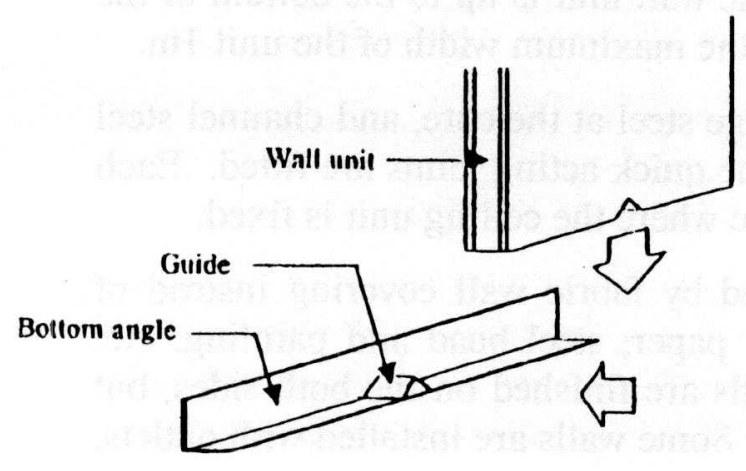

Figure 4, Assembly of wall unit

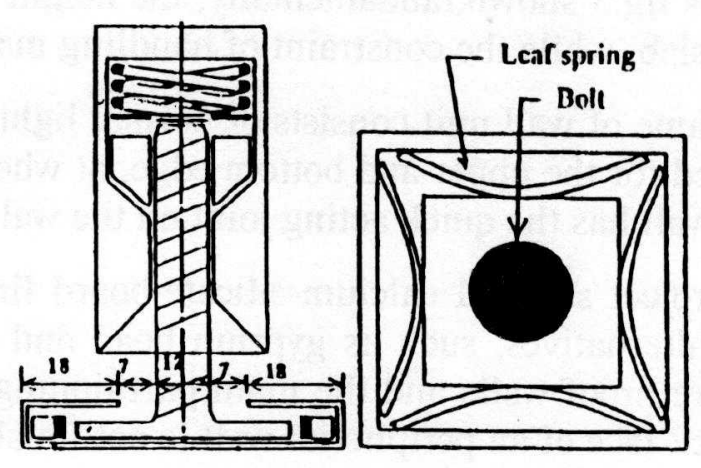

Figure 5. Detail of quick acting joint

The pieces of quick acting joint are set on the upper and the bottom angle, and the guide pieces are set on the bottom angle before fabrication, the upper angle is set on the face of the bottom beam flange and the bottom angle is set on the floor in accordance with the datum line marked. The guide piece makes the positioning of the unit by robot easily.

After the fabrication of all wall unit is compled, the beam unit is fixed . there are two types of beam unit, one is used for the beam not connected with the wall unit and has $U$ section, this unit can be fixed to the beam with the quick acting joints while the unit is raising from under the beam. The other is made of two $\mathrm{L}$ section parts, and used for the beam connected with the wall unit, this unit is fixed to the beam with the quick acting joint while the unit is pushed holizontaly from both side of the beam.

\subsection{Ceiling System}

The ceiling unit is composed of the frame unit and the finish panel. Figure 6 shows the configuration of the frame unit which supports the finish panel installed the equipment (illumination and detector etc.) and the finish board. The frame unit has a pair of legs to be connected to the slab with the quick acting joints attached on the top of the legs. The legs can be folded so that a large amount of units are transported at a time. The connecting of electric wiring for the equipment is completed on the same time as installing the finish panel.

Figure 7 shows the configuration of the finish panel. The finish panel composes the final finished face of the ceiling and has two types, the one has finishing materials, reinforce plate, screw of the quick acting joint, illumination, detector and wiring, the other has same composition exceptillumination and detector. Rock wool acoustic board is used for the finishing material. 


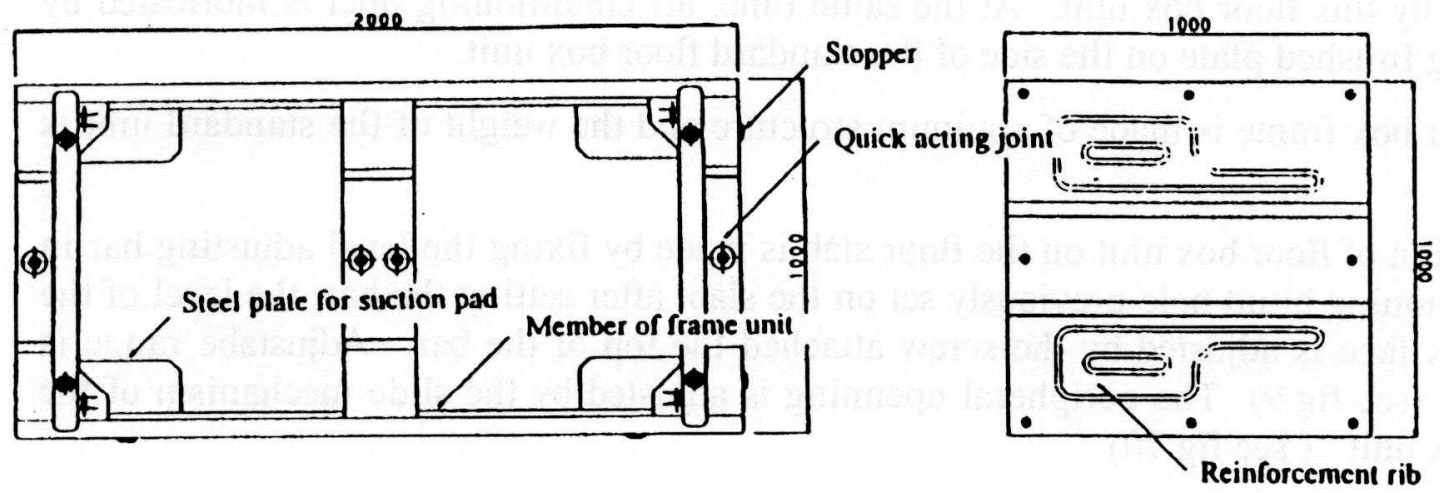

Figure 6, Ceiling frame unit

Figure 7 , Ceiling finish panel

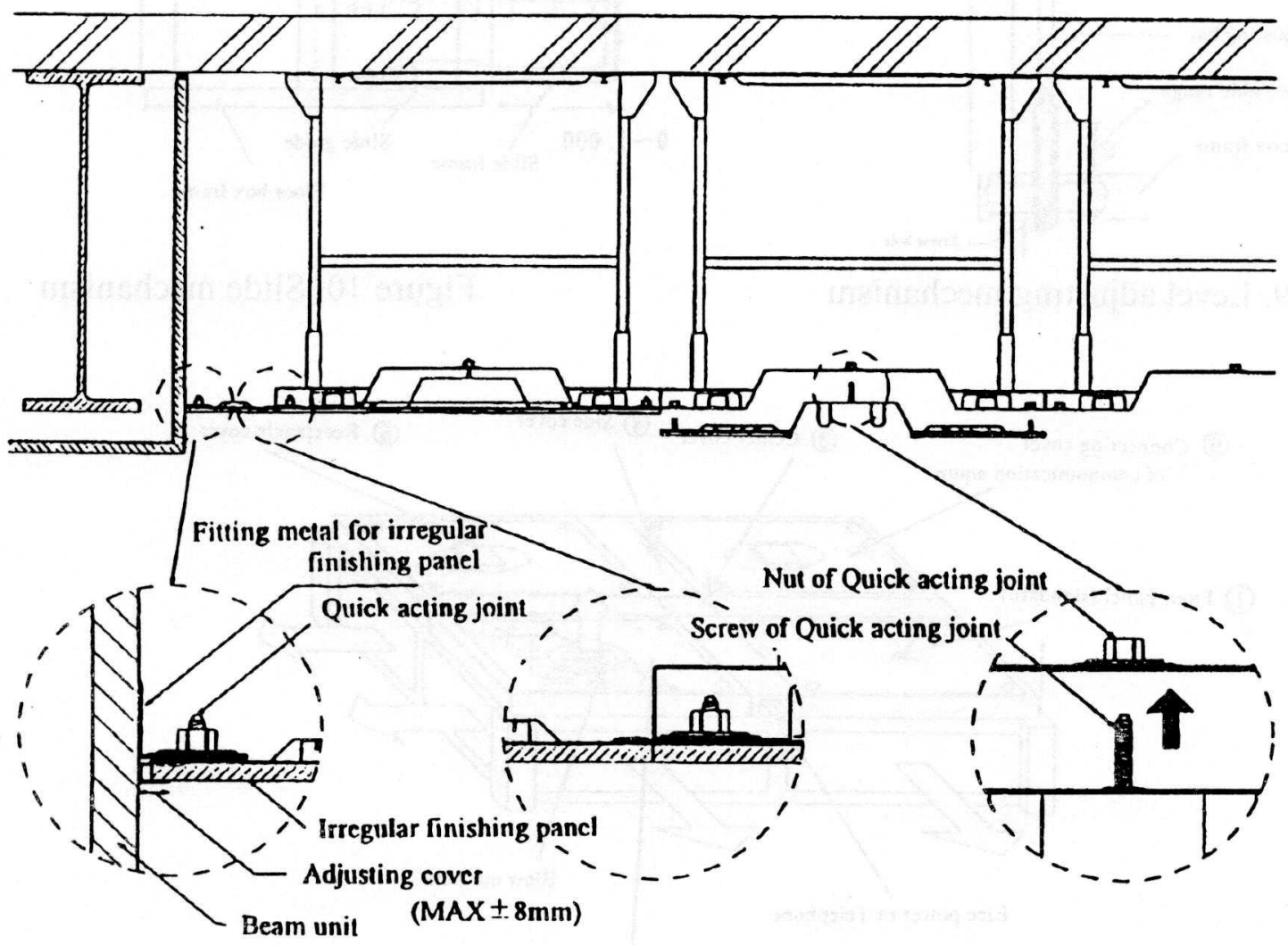

Figure 8, Ceiling system outline

\subsection{Foor System}

The characteristic of this floor system is that the current arrangement of some functions provided on ceiling is moved on floor. Having considerd the necessary function of the equipment and the arrangement for the living space, we decided to develop frame constructed floor box unit with necessary function and supporting floor finishing 
material by this floor box unit. At the same time, air conditioning duct is fabricated by attaching finished plate on the side of the standard floor box unit.

The floor box frame is made of alminum structure and the weight of the standard unit is $18.3 \mathrm{~kg}$.

Installation of floor box unit on the floor slab is made by fixing the level adjusting bar in the positioning blind hole previously set on the slab, after setting the bar, the level of the floor box face is adjusted by the screw attached the top of the bar. Adjustabe range is $+10 \mathrm{~mm}$. (see fig.9) The peripheral openning is adjusted by the slide mechanism of the floor box unit. ( see fig.10)

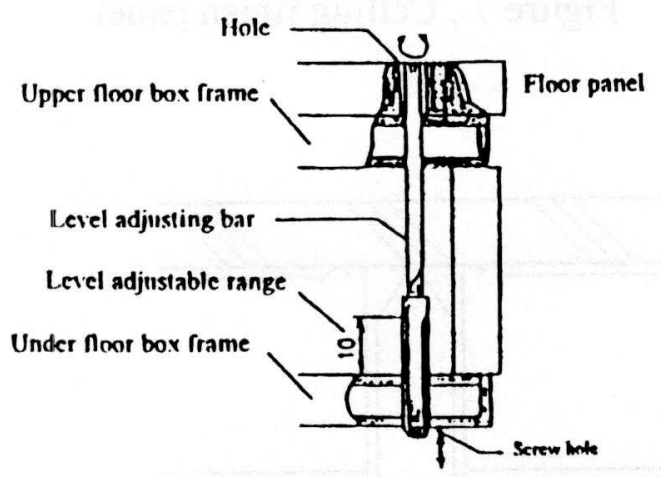

Figure 9. Level adjusting mechanism

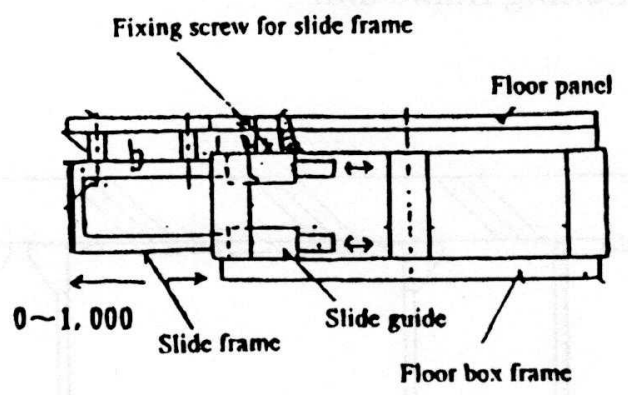

Figure 10. Slide mechanism

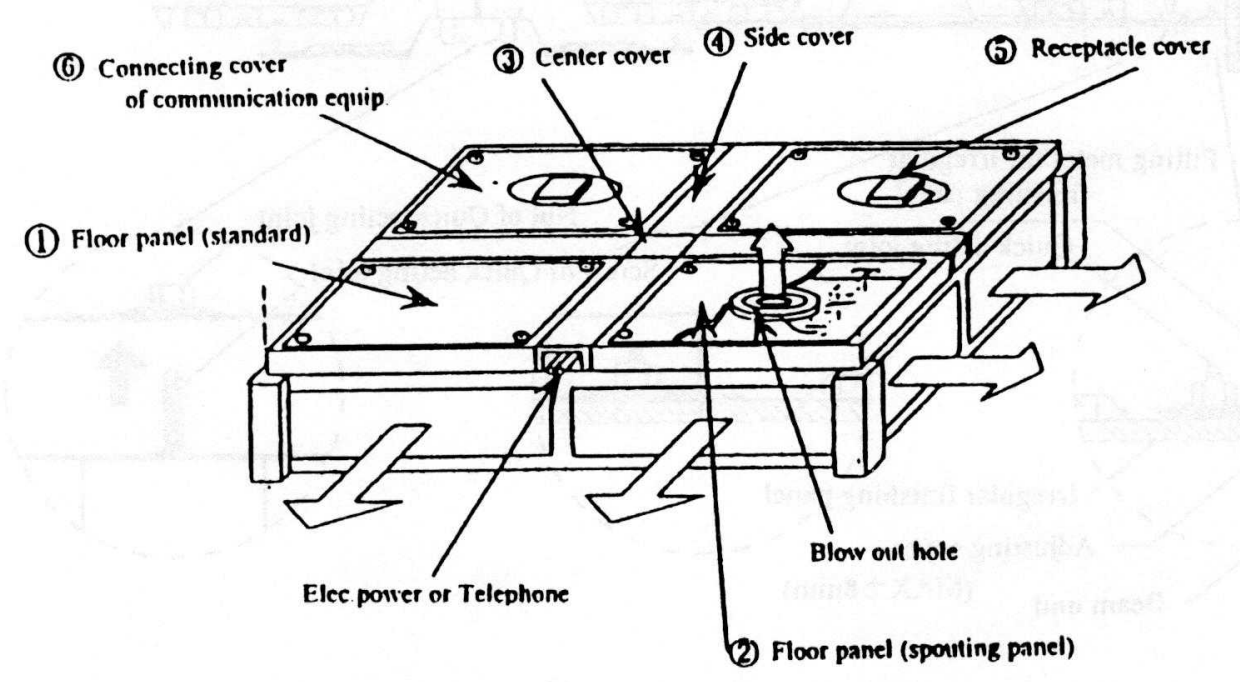

Figure 11 Construction of floor box unit.

\section{THE SCHEMATIC DESIGN OF CONSTRUCTION ROBOTS}

The development of construction robots calls for the issues indicated in the diagram shown in the figure 12 . The theme of the project this year is to clarify the schematic design of construction robot, which is explained by the four items shown in the left side of the diagram. 
The function of the construction robot can be divided into the two main functions: Holding and fabricating function, and locomotive function.

Module robot which has some versatility to different works, by exchanging its handling devise, is somewhat advantageous, however, the project didn' $t$ decide to adapt module robot after considering the work efficiency and work process as well as the configuration of each unit and the movement in the assembly process.

The mechanism of the locomotive function is common to each construction robot, therefore, the locomotion mechanism of the robots can be designed by the same way based on the same concept,even though the weight of each unit is differnt. On the construction site, each unit system is carried out by each robot, for each work, shown in the figure 13 .

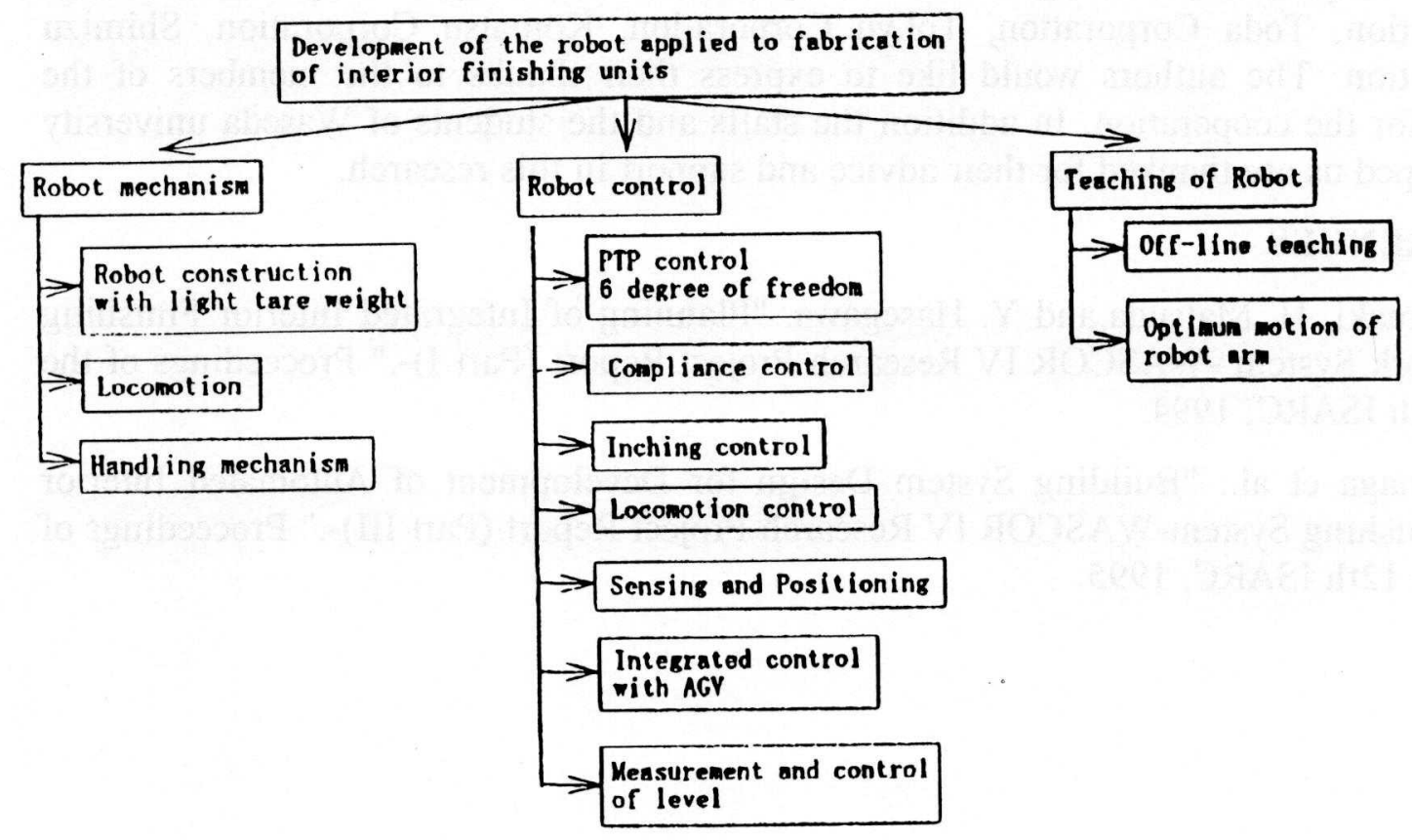

Figure 12, Problem of robot development

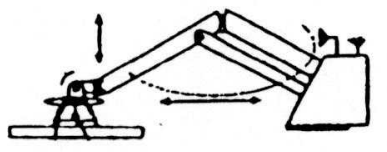

Wall system

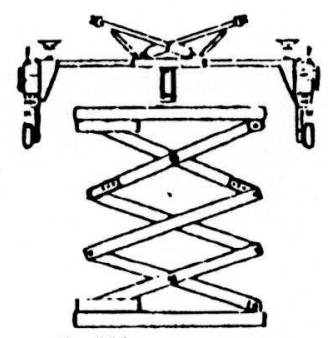

Ceiling system

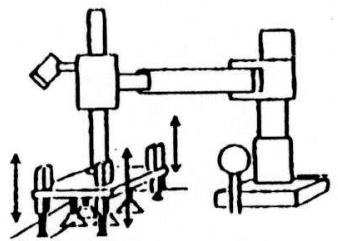

Floor system
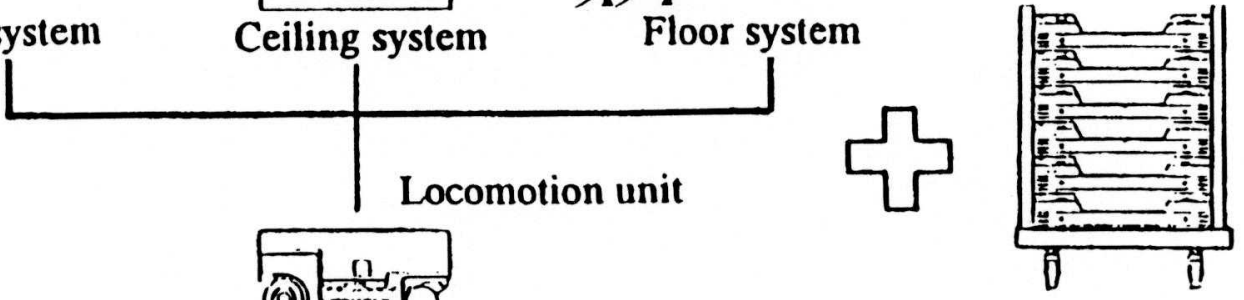

Figure 13, Robot composition image chart 


\section{SUMMARY}

In this report (PART III),the concept of applying each unit for each finishing work is proposed as a suilable interior finishing work system for automation, and the suitable stractural work method is also developed. At the same time, an image of the robots for the installation of each work is reported. The information control system reported last sysmposium as PART I, and the further study of this field together with the robot design will be reported next year.

\section{ACKNOWLEDGEMENT}

This study is a part of the WASCOR research project, a multi-client research project organized by the System Sience Institute of Waseda University and the following 11 companies: Fujita Corporation, Hazama Corporation, Hitachi Zosen Corporation, Kajima Corporation, Kumagai Gumi Corporation, Sato Kogyo Corporation, Taisei Corporation, Toda Corporation, Tokyu Corporation, Komatsu Corporation, Shimizu Corporation. The authors would like to express their thanks to the members of the project for the cooperation. In addition the staffs and the students of Waseda university who helped us are thanked for their advice and support in this research.

\section{REFERENCES}

[1] Tamaki, H. Matsuda, and Y. Hasegawa. "Planning of Integrated Interior Finishing Work System -WASCOR IV Research Project Report (Part I)-." Proceedings of the 11th ISARC, 1994.

[2] Sunaga et a1.. "Building System Design for Development of Automated Interior Finishing System-WASCOR IV Research Project Report (Part III)-." Proceedings of the 12th ISARC, 1995. 